\title{
CRIMINALIZAÇÃO DO DISCURSO DE ÓDIO NO BRASIL COM BASE NOS TRATADOS INTERNACIONAIS
}

\section{CRIMINALIZATION OF HATE SPEECH IN BRAZIL BASED ON INTERNATIONAL TREATIES}

\author{
${ }^{1}$ Pedro Lima Marcheri \\ ${ }^{2}$ Vinicius Roberto Prioli de Souza
}

\section{RESUMO}

Todos os países criminalizam o discurso de ódio ou alguma forma de discriminação. Todavia, não há um padrão para que tal criminalização ocorra. Os tratados internacionais podem prover uma alterativa adequada para o alinhamento da legislação criminal aos sistemas mais modernos que criminalizam o discurso de ódio. Por meio de revisão bibliográfica, e jurisprudencial, apresentam-se aspectos relativos a tal adaptação. Concluiu-se que o descumprimento das exigências de criminalização do Brasil frente aos pactos que é signatário enseja o controle de convencionalidade na criminalização do ódio.

PALAVRAS-CHAVE: Discurso de Ódio; Tolerabilidade; Tratados Internacionais; Controle de Convencionalidade; Crime

\begin{abstract}
All countries criminalize hate speech or some form of discrimination. However, there is no standard for such criminalization takes place. International treaties can provide a suitable alterative to the alignment of criminal law to most modern systems that criminalize hate speech. Through literature review and case law, we present aspects of such adaptation. It was concluded that the failure of the criminalization requirements of the Brazil facing agreements that is a signatory entails the conventionality control the criminalization of hate.
\end{abstract}

KEYWORDS: Hate Speech; Tolerability; International Treaties; Conventionality Control; Crime

\footnotetext{
${ }^{1}$ Doutorando em Direito pela Instituição Toledo de Ensino - ITE, São Paulo, SP, (Brasil). Mestre em Direito pelo Centro Universitário Eurípedes de Marília - UNIVEM, São Paulo, SP, (Brasil). Professor no Centro Universitário Católico Salesiano Auxilium UNISALESIANO, São Paulo, SP, (Brasil). E-mail.: pedrolimaadvogados@hotmail.com.

${ }^{2}$ Doutorando em Direito pela Instituição Toledo de Ensino - ITE, São Paulo, SP, (Brasil). Mestre em Direito pela Universidade Metodista de Piracicaba -UNIMEP, Piracicaba, SP, (Brasil). Professor Centro Universitário Católico Salesiano Auxilium - UNISALESIANO, São Paulo, SP, (Brasil). E-mail.:
}

Revista Brasileira de Direito Internacional le-SSN: 2526-0219| Curitiba | v. 2 | n. 2 | p. 193 - 213 | Jul/Dez. 2016. 


\section{INTRODUÇÃO}

Na criminalização do discurso de ódio, atualmente a maior parte dos tribunais têm se utilizado de uma interpretação própria, baseada em critérios estabelecidos no direito pátrio. Esta interpretação basicamente contempla critérios como a solução de conflitos dos direitos fundamentais à liberdade de expressão e da igualdade negativa (direito à não discriminação). De tal sorte, vem sendo ignorado que os parâmetros adequados para esta interpretação já são previstos no direito internacional público, por meio de tratados ou convenções em que os países signatários estabelecem padrões para tal criminalização.

Tal situação acaba por gerar incoerências nas decisões de casos em que o discurso de ódio é de natureza semelhante. Veja-se o caso da eleição de fatores discriminatórios em cada sistema penal - no Brasil criminaliza-se o preconceito em razão da raça, cor, etnia, religião, procedência nacional e condição de pessoa com deficiência; na Bolívia este rol se estende para mais de vinte critérios, como a filiação político-partidária, condição de renda e questões de homoafetividade.

O presente estudo tem por finalidade estudar a pertinência de novos critérios jurídicos que serviriam como base para a correta criminalização do discurso de ódio, como a harmonização das leis e jurisprudências pátrias com os inúmeros tratados que o Brasil é signatário. Ademais, pretende-se elucidar os parâmetros utilizados pelas Cortes internacionais para a tipificação de condutas discriminatórias e em qual medida tais padrões possam ser incorporados ou contribuir com a legislação brasileira.

\section{PADRÃO JURISPRUdENCIAL NA CORTE EUROPEIA DE DIREITOS HUMANOS}

Partiremos do seguinte exemplo: o ressurgimento do antissemitismo na Alemanha e em toda Europa Ocidental, fenômeno este que foi e a inda é tema em voga para as democracias do velho continente.

No início de 2001 os países da União Europeia, de forma inédita, organizaram um boicote à Áustria em razão da aprovação do Partido Nacional na nova formação partidária 
governamental. O Partido, presidido por Jorge Heider, advogando políticas xenofóbicas e tem posições extremistas no combate aos imigrantes, além de idolatrar as políticas econômicas de Adolf Hitler. Ademais existem acusações não confirmadas do adestramento de jovens para atentados raciais contra judeus e outras minorias. Em suma, o Estado alemão solicitou à Suprema Corte da Alemanha a extinção ou supressão d o Partido Democrático Nacional (BOYLE, 2001).

A crescente tensão gerada pelo tema tem levado gradualmente os países europeus a estabelecer políticas de criminalização do discurso revisionista e de negação do Holocausto; prática esta que já podia ser constatada desde 1945, ao final de Segunda Guerra. Os campos de concentração nem ainda haviam sido abertos à visitação pública e imprensa internacional já publicava as primeiras leituras que banalizavam a verdade dos fatos (BOYLE, 2001).

Com maior sedimentação do revisionismo histórico antissemita nos anos 1970, o material era diversificado e incluía desde o simplório panfleto com a frase 'O Holocausto foi um Embuste, vamos torná-lo Real!' à pesquisas históricas com pretenso conteúdo científicoacadêmico $^{3}$, como no caso do Journal for Historical Review. Em tais publicações são encontradas minimizações de naturezas diversas, com o a morte de apenas algumas centenas de judeus (ao invés do número aproximado de seis milhões); ou a impossibilidade da utilização das câmaras de gás em Auschwitz dada à ausência de desenvolvimento tecnológico para tanto (BOYLE, 2001).

A lei francesa, conhecida como Lei Gaysott, de 1990, criminaliza a banalização ou negação dos fatos históricos do holocausto ou a justificação do genocídio. A contestação pública da existência dos crimes julgados no Tribunal de Nuremberg também foi criminalizada. O tipo penal foi incluído em amplo estatuto de criminalização do racismo, antissemitismo ou xenofobia. O tema também foi julgado pela CERD (Comitê de Eliminação da Discriminação Racial) por inúmeras vezes. Um montante considerável de recursos contra as leis de negação do holocausto foram reiteradamente negados pela Corte Europeia, sob o manto da relativização da garantia da liberdade de expressão no caso do discurso de ódio. (BOYLE, 2001)

\footnotetext{
${ }^{3} \mathrm{O}$ caso do historiador David Irvine mostra algumas peculiaridades interessantes. Irvine, um notório negacisonista ajuizou uma demanda contra a Editora Penguin, alegando a violação de sua honra no livro Denying the Holocaust: The Growing Assault on Truth and Memory, de autoria da escritora Deborah Lipstadt. Na obra Irvine é referido como antissemita, partidário de Hitler e falso historiador. A corte ratificou as alegações da defesa, ressaltando que a trajetória profissional do autor corroborava para sua retratação negativa (BOYLE, 2001).
} 
Em 1987, o caso do líder da Frente Nacional (partido francês de extrema-direita) Jean Marie Le Pen repercutiu no cenário europeu. Le Pen foi multado por declarar publicamente em uma entrevista de rádio que o genocídio nos campos de concentração foi apenas 'point de detail' (um mero detalhe). Em contexto semelhante, o historiador Robert Faurisson, em entrevista para um periódico na França, teceu críticas à Lei Gaysott ressaltando sua ameaça para a liberdade de expressão, e afirmando sua convicção que o holocausto em câmaras de gás jamais existiu nos campos nazistas. Com base nesta última assertiva, em 1991 o Tribunal de Grande Instância de Paris (TGI) condenou Faurisson com base na Lei. Posteriormente, ele interpôs recurso perante o Comitê de Direitos Humanos, com base no artigo 19 da Convenção de Direitos Políticos e Civis, com esteio na garantia da liberdade de expressão. O Comitê manteve a condenação, pois considerou uma interferência justificável ao direito de liberdade de expressão. Foram ratificados os argumentos da promotoria francesa, no sentido de que a negação do genocídio nazista apresenta-se como a forma mais comum do antissemitismo na França (BOYLE, 2001).

Juntas a Corte Europeia de Direitos Humanos e o Comitê de Ministros do Conselho Europeu - Comissão Europeia de Direitos Humanos - supervisionaram o cumprimento das obrigações acordadas pelas nações que ratificaram a Convenção, desde o mês de julho de 1954 à outubro de 1999. Com a extinção da Comissão, a Corte Europeia tornou-se o órgão permanente responsável pelo julgamento dos casos relativos à matéria convencionada em $1^{\circ}$ de novembro de 1998 (HATE SPEECH, 2015).

O texto da Convenção menciona expressamente os parâmetros para a liberdade de expressão e a proibição da discriminação:

Artigo $10^{\circ}$ - Liberdade de expressão

1. Qualquer pessoa tem direito à liberdade de expressão. Este direito compreende a liberdade de opinião e a liberdade de receber ou de transmitir informações ou ideias sem que possa haver ingerência de quaisquer autoridades públicas e sem considerações de fronteiras. O presente artigo não impede que os Estados submetam as empresas de radiodifusão, de cinematografia ou de televisão a um regime de autorização prévia.

2. O exercício desta liberdade, porquanto implica deveres e responsabilidades, pode ser submetido a certas formalidades, condições, restrições ou sanções, previstas pela lei, que constituam providências necessárias, numa sociedade democrática, para a segurança nacional, a integridade territorial ou a segurança pública, a defesa da ordem e a prevenção do crime, a proteção da saúde o u da moral, a proteção da honra ou dos direitos de outrem, para impedir a divulgação de informações confidenciais, ou para garantir a autoridade e a imparcialidade do poder judicial. [...]

Artigo $14 .^{\circ}$ - Proibição de discriminação

Revista Brasileira de Direito Internacional le-SSN: 2526-0219| Curitiba | v. 2 | n. 2 | p. 193 - 213 | Jul/Dez. 2016. 
O gozo dos direitos e liberdades reconhecidos na presente Convenção deve ser assegurado sem quaisquer distinções, tais como as fundadas no sexo, raça, cor, língua, religião, opiniões políticas ou outras, a origem nacional ou social, a pertença a uma minoria nacional, a riqueza, o nascimento ou qualquer outra situação. (CONSELHO DA EUROPA, 2015)

A questão do cotejo entre a democracia e os direitos fundamentais é sustentada por Alves (2012, p. 118-119) como um problema absolutamente típico das nações de modernidade tardia: "Na Europa, a questão dos direitos de minorias se polariza em torno de questões culturais (associadas à migração, etc.), na periferia do sistema" e na medida em que tais questões preponderantemente se relacionam à plenitude do exercício dos direitos civis e sociais, abre-se um espaço cada vez mais profícuo para a "necessidade de uma nova fundamentação construída a partir do mundo da vida daqueles que são os destinatários principais desses direitos na contemporaneidade", a saber, do prisma das próprias minorias como uma alternativa à hermenêutica tradicional, anódina e indiferente às carências jurídicas destas.

Weber (2009, p. 39) indica os parâmetros utilizados para a inflexão do discurso de ódio nos tribunais europeus, com especial enfoque na posição estrutural do ofensor e da minoria alvo:

\begin{abstract}
The Court takes into account the status of the victim of the opinion expressed. In general, it considers that the limits of acceptable criticism are accordingly wider as regards a politician as such than as regards a private individual. Unlike the latter, the former inevitably and knowingly lays himself open to close scrutiny of his every word and deed by both journalists and the public at large, and he must consequently display a greater degree of tolerance. This is all the more true if the criticism target governments, in the sense that in a democratic system its actions or omissions must be subject to the close scrutiny not only of the legislative and judicial authorities but also of the press and public opinion. Furthermore, the dominant position which the Government occupies makes it necessary for it to display restraint in resorting to criminal proceedings, particularly where other means are available for replying to the unjustified attacks and criticisms of its adversaries or the media.
\end{abstract}

A Corte Europeia de Direitos Humanos no caso Handyside vs. the United Kingdom ${ }^{4}$ fundamentou em sua decisão que a liberdade de expressão constitui um dos fundamentos essenciais de uma democracia contemporânea, o pressuposto básico para seu progresso e para o desenvolvimento de todos os indivíduos. O artigo $10, \S 2^{\circ}$ da Convenção Europeia de

\footnotetext{
${ }^{4}$ Handyside v. the United Kingdom [1976] \$49. Pleito no 5493/72. Extrato do julgamento para consulta no endereço eletrônico da corte. Disponível em: 〈http://hudoc.echr.coe.int/sites/eng/pages/search.aspx?i=001-57499\#\{"itemid":["001-57499"]\}>. Acesso em: 10. jun. 2016.
} 
Direitos Humanos aplica-se não somente na hipótese de informações ou ideias abstratas que são favoravelmente recebidas ou consideradas como tema inofensivo ou indiferente, mas também a aquelas que ofendem, chocam ou perturbam o Estado ou grupo social. Tais demandas são inerentes ao pluralismo, tolerância e abertura de ideias (pluralism, tolerance and broadmindedness) sem os quais não existiria uma verdadeira sociedade democrática. Deste modo, a Corte menciona que toda a formalidade, condição, restrição ou penalidade (every formality, condition, restriction or penalty) imposta deve ser compatível e hábil à proporcionar a legitimação dos fins propostos.

O respeito pela igual dignidade humana e a tolerância foram ratificados como a pedra angular de uma sociedade democrática e plural (la tolérance et le respect de l'égale dignité de tous les êtres humains constituent le fondement d'une société démocratique et pluraliste) ${ }^{5}$ pela Corte Europeia de Direitos Humanos no caso Erbakan vs. Turkey ${ }^{6}$. Discorreu ainda que, por questões principiológicas, em determinadas sociedades democráticas poderá ser reconhecida a necessidade de sancionar ou prevenir todas as formas de expressão que dissemine, incitem, promovam ou justifiquem o ódio baseado na intolerância. Reitera ainda o critério da capacidade e compatibilidade finalística para as formalidades, condições, restrições ou penalidades que cerceiem parcial ou integralmente a liberdade de expressão constitucionalmente garantida (inicialmente adotado em Handyside vs. the United Kingdom), ainda que diante de um caso de discurso de ódio.

Identificou-se que a Corte Europeia nos julgamentos das demandas de contenção ou conflito dos direitos fundamentais de liberdade de expressão e igualdade (nãodiscriminatória) ${ }^{7}$, destacando as condenações de natureza cível ou criminal em razão de práticas de intolerância e racismo, adotou dois modelos padronizados de fundamentação:

\section{I) Proibição do discurso de ódio por abuso do garantia da livre de expressão:} exclusão da tutela conferida pelo Artigo 17 da Convenção - proibição de abuso de direitos ${ }^{8}$;

\footnotetext{
${ }^{5}$ A transcrição juramentada da expressão no idioma turco: "Buna ilişkin olarak AİHM, hoşgörünün, herkesin onuruna ve saygınlığına eşit oranda saygı gösterilmesinin demokratik ve çoğulcu bir toplumun temelini oluşturduğunu hatırlatmaktadır".

${ }^{6}$ Erbakan v. Turkey [2006] §56. Pleito no 59405/00. Extrato do julgamento para consulta no endereço eletrônico da corte. Disponível em: <http://hudoc.echr.coe.int/sites/eng/pages/search.aspx\#\{"itemid":["001-76232"]\}>. Acesso em: 10. jun. 2016.

${ }^{7}$ Incidentalmente a garantia da legalidade também era integrada na demanda, pois o questionamento da criminalização específica do racismo por outras minorias, em determinados precedentes, necessariamente abordava a fundamentação de limites imanentes e a construção e interpretação dos delitos de ódio com base na garantia legalidade penal.

8 “Artigo 17. ${ }^{\circ}$ - Proibição do abuso de direito: Nenhuma das disposições da presente Convenção se pode interpretar no sentido de implicar para um Estado, grupo ou indivíduo qualquer direito de se dedicar a atividade ou praticar atos em ordem à destruição dos direitos ou liberdades reconhecidos na presente Convenção ou a maiores limitações de tais direitos e liberdades do que as previstas na Convenção." (CONSELHO DA EUROPA, 2015)
}

Revista Brasileira de Direito Internacional le-SSN: 2526-0219| Curitiba | v. 2 | n. 2 | p. 193 - 213 | Jul/Dez. 2016. 
II) Relativização da liberdade de expressão: prevalência da garantia do Artigo 10, $\S 2^{\circ}$ da Convenção - relativização da liberdade de expressão em razão do discurso de ódio, estabelecendo restrições e limites para a prática.

Estes padrões foram estabelecidos por meio da sedimentação de precedentes, compondo a tutela jurisdicional da Corte em diferentes escalas. O critério de aplicação de cada um se pauta no grau ou dimensão da violação dos valores fundamentais da Convenção. $\mathrm{Na}$ hipótese em que a retórica, embora se constitua como expressão de intolerância (hate speech), não tiver capacidade para destruir valores funda mentais da Convenção, a reserva estabelecida pela Corte tende a ser parcial, fundamentando-se no segundo modelo (prevalência do artigo $10, \S 2^{\circ}$ ). Caso a prática de ódio negue integralmente valores fundamentais garantidos na Convenção, o balanceamento realizado pela Corte tende em reconhecer a supressão total do conteúdo discriminatório.

Conforme o informativo da Corte Europeia, as restrições impostas com base no artigo 10 serão fixadas tendo os seguintes objetivos:

This provision is aimed at preventing persons from inferring from the Convention any right to engage in activities or perform acts aimed at the destruction of any of the rights and freedoms set forth in the Convention. Restrictions deemed necessary in the interests of national security, public safety, the prevention of disorder or crime, the protection of health or morals and the protection of the rights and freedoms of others. (HATE SPEECH, 2014)

Conforme o informativo da Corte Europeia, as restrições impostas com base no artigo 10 serão fixadas tendo os seguintes objetivos:

Tendo como exemplo o caso Seurot vs. France ${ }^{9}$ no qual a Corte julgou a divulgação de um boletim em um colégio particular francês contendo declarações xenofóbicas contra os imigrantes africanos e islâmicos que "malditos imigrantes do norte da África e hordas muçulmanas inassimiláveis" que "invadiam até os territórios mais remotos da França, construindo suas mesquitas por toda parte" ${ }^{10}$. Nesta hipótese admitiu-se a violação integral dos valores da Convenção, ponderando a Corte Europeia que não há dúvidas que qualquer consideração de embate frontal aos valores consagra dos nesta Convenção devem ser retirados

\footnotetext{
${ }^{9}$ Seurot vs. France [2004] §50. Pleito no 57383/00. Extrato do julgamento para consulta no endereço eletrônico da corte. Disponível em: <http://hudoc.echr.coe.int/sites/eng/pages/search.aspx?i=001-45005\#\{"itemid":["001-45005"]\}>. Acesso em: 10. jun. 2016.

${ }^{10}$ Texto original em frânces: "Maudits Français d'Afrique du Nord, des hordes musulmanes inassimilables, débarqueraient et investiraient les plus reculés de nos cantons. [...] Construisent partout des mosquées".
}

Revista Brasileira de Direito Internacional le-SSN: 2526-0219| Curitiba | v. 2 | n. 2 | p. 193 - 213 | Jul/Dez. 2016. 
da proteção do artigo 10 em razão do abuso de direito da liberdade de expressão, ratificando a condenação em 18 de maio de 2004.

\section{HARMONIZAÇÃO NORMATIVA E JURISPRUDENCIAL E O CONTROLE DE CONVENCIONALIDADE NA CRIMINALIZAÇÃO DO ÓDIO}

Reconhecidamente há influência recíproca entre a jurisprudência constitucional e a convencional, na medida em que tendem a convergir na composição de precedentes, procedimentos adotados, e a fundamentação dos julga dos. É um sistema de retroalimentação, a saber, um nexo paulatinamente mais estreito e reiterado entre as ordens jurídicas internas e a seara internacional.

A análise da criminalização do racismo é conduzida, via de regra, em âmbito interno à luz do mandado constitucional (art. 5 $5^{\circ}$ XLII). Contudo, exige-se um deslocamento mais amplo para tal teorização que prescinde, as mais das vezes, de uma reflexão acerca da compatibilidade do tipo penal com as normas internacionais ratificadas pela República Federativa e incorporadas ao bloco de constitucionalidade. Aferir os padrões de juridicidade na incorporação de outras minorias à equivalência da prática do racismo poderá envolver não só a hermenêutica jurídica (em suas diferentes espécies), mas também o controle de convencionalidade para a formação de precedentes sólidos em conformidade com o Direito Internacional.

Não há vedação ${ }^{11}$ na Carta Magna brasileira que o controle de convencionalidade seja realizado por corte internacional, ainda que o mesmo ato tenha sido objeto de controle de constitucionalidade em âmbito interno. A bem da verdade, nossa Constituição admite e até incentiva o viés internacional, tendo como base dispositivos que: instituem como primados das relações internacionais a "prevalência dos direitos humanos" (art. 4", II) e a "solução pacífica dos conflitos" (art. $\left.4^{\circ}, \mathrm{VII}\right)$; não excluem outros "direitos e garantias" fundamentais decorrentes dos tratados internacionais (art. $5^{\circ}, \S 2^{\circ}$ ) e atribuem a estes a equivalência às emendas constitucionais, mediante aprovação com requisitos específicos (art. $5^{\circ}, \S 3^{\circ}$ ); acatam a "jurisdição de Tribunal Penal Internacional" (art. 5', § 4') e defendem a "formação de um tribunal internacional dos direitos humanos" (art. $7^{\circ}$ do Ato das Disposições Constitucionais Transitórias); por fim, também autorizam o modificação da competência da persecutio

\footnotetext{
${ }^{11} \mathrm{E}$ ainda que tal vedação existisse, não haveria respaldo de sua validade no direito internacional.
} 
criminis, na hipótese de graves violações de direitos humanos, "com a finalidade de assegurar o cumprimento de obrigações decorrentes de tratados internacionais de direitos humanos" (art. 109, § 5 $)$ (ROTHENBURG, 2013).

Determinada norma ou ato jurídico pode ter confirmada sua constitucionalidade, ou seja, a aferição positiva de conformidade deste com os padrões de juridicidade - referência constitucional-, e ser considerado inválido pelo prisma convencional. Destarte, o controle de convencionalidade afere a mesma validade, contudo, tendo como parâmetro o tratado internacional, e não mais a Constituição. Portanto, o controle de convencionalidade pressupõe a incompatibilidade da norma ou ato com o critério convencional, enquanto que este ato também pode violar os preceitos constitucionais (hipótese em que também caberá o controle de constitucionalidade) ou não.

Rothenburg (2013, p. 684) leciona sobre os preceitos da convencionalidade:

\begin{abstract}
Um ato pode ser considerado válido do ponto de vista constitucional, ou seja, ser aprovado pelo controle de constitucionalidade, mas inválido do ponto de vista convencional, ou seja, ser reprovado pelo controle de convencionalidade. Ou viceversa: apesar de considerado compatível com o parâmetro convencional, o ato pode ser tido como incompatível com o parâmetro constitucional. [...]

A análise em âmbito interno da compatibilidade de um ato com a Constituição normalmente não suscita reflexões acerca da convencionalidade. O que pode acontecer e ocorre com cada vez mais frequência é invocação, quando do controle de constitucionalidade, de situações semelhantes no Direito Internacional (e no Direito de outros Estados), bem como da jurisprudência das cortes internacionais (e das cortes estrangeiras). Uma influência recíproca certamente impulsionada pela facilidade de comunicação no mundo contemporâneo.
\end{abstract}

Dissertando ainda sobre o panorama da validade dos atos e normas jurídicas, ressalta-se que o desarranjo com o parâmetro constitucional ou convencional é suficiente para que o ato seja destituído de validade. Esta é a inexorável tendência do direito contemporâneo, na qual a esfera internacional galga um patamar diferenciado, na qual é cada vez mais conhecida e aplicada. Não mais se tolera que um ato subsista mostrando-se incompatível com as normas internacionais, a saber, infringência à convencionalidade, ao mesmo tempo em que não se abdica da imprescindibilidade da congruência com a Constituição no âmbito doméstico de cada Estado. Neste raciocínio, a norma deverá ter sustentação concomitante nos parâmetros de constitucionalidade e de convencional idade (ROTHENBURG, 2013). Conforme propõe Neves (2012, p. 253), a interação dos direitos fundamentais nas searas convencionais e pátria é fundamental, de modo em que obedecem à tendência na qual "os direitos humanos pretendem valer para o sistema jurídico mundial de níveis múltiplos, ou 
seja, para qualquer ordem jurídica existente na sociedade mundial (não apenas para a ordem jurídica internacional)".

Ratifica Carnota (2012, p. 13) a relevância do controle de convencionalidade, sobretudo na interação das Supremas Cortes na América Latina com a Corte Interamericana de Direitos Humanos:

Latin American Constitutional and Supreme Courts (in centralized and decentralized adjudication scenarios) have begun to rely on IACHR case law for their own rulings. Domestic judicial actors realized that these new criteria enjoyed widespread recognition, since this body of law sprung from the democratization process of the 1980s. The Court became in this way a source of new human rights judicial stances in both its adversarial and advisory functions. Member States were now more eager to abide by Inter-American Court judgments not only out of its prestige; they also had their own stake on its membership, even though judges do not formally represent States on an official capacity because they are selected on grounds of personal intellectual proficiency.

Não obstante, para a validade integral de determina do ato é necessário que este encontre fundamento e respaldo em ambas as searas. Este deve ser conforme a Constituição do país e também respeitar as convenções internacionais, acatadas pelo Estado no qual se origina, para ser considerado válido. Por exemplo, a Lei n. 6.683/1979 (Lei da Anistia) teve declarada sua incompatibilidade com a Convenção Americana de Direitos Humanos pela respectiva Corte Interamericana, muito embora o prévio reconhecimento de congruência constitucional pelo STF.

De igual modo, poder-se-ia afirmar a existência de incompatibilidade entre a legislação que criminaliza o racismo e outras discriminações com os parâmetros convencionais, embora sua constitucionalidade tenha sido reconhecida pela Corte Constitucional brasileira? Suscita-se tal questionamento tendo como premissa o conteúdo do artigo 13 (5) da Convenção Interamericana de Direitos Humanos, que impõe a vinculação da criminalização das práticas de apologia ao ódio nacional, racial ou religioso à incitação de violência ilícita ou outra ação similar ${ }^{12}$.

A interpretação restritiva da expressão "violência ilícita", no sentido de compreender apenas a agressão física ou moral dirigida especificamente para um indivíduo ou grupo, poderia refletir na não convencionalidade da criminalização da apologia abstrata ao racismo,

\footnotetext{
12 “Any propaganda for war and any advocacy of national, racial, or religious hatred that constitute incitements to lawless violence or to any other similar action against any person or group of persons on any grounds including those of race, color, religion, language, or national origin shall be considered as offenses punishable by law." (CONVENÇÃO, 1969).
}

Revista Brasileira de Direito Internacional le-SSN: 2526-0219| Curitiba | v. 2 | n. 2 | p. 193 - 213 | Jul/Dez. 2016. 
na qual a defesa teórica de ideias como a justificação do genocídio ou a superioridade racial, seriam incompatíveis com a ordem constitucional, porém de acordo com os parâmetros convencionais (abalizados pela jurisprudência da Suprema Corte Americana).

Este é um caso clássico de transconstitucionalidade, um desarranjo material nos próprios parâmetros fixados nos diversos tratados que versam sobre os direitos fundamentais, especialmente na proibição do discurso do ódio e racismo, como a Declaração Universal dos Direitos Humanos (art. 2) que pró́be a discriminação de qualquer espécie, "nomeadamente de raça, de cor, de sexo, de língua, de religião, de opinião política ou outra, de origem nacional ou social, de fortuna, de nascimento ou de qualquer outra situação"; o Pacto Internacional sobre Direitos Civis e Políticos (art. 20) que estabelece o mandado proibitório de "qualquer propaganda em favor da guerra" ou "qualquer apologia do ódio nacional, racial ou religioso que constitua incitamento à discriminação, à hostilidade ou à violência"; ou mesmo a Convenção Internacional sobre a Eliminação de Todas as Formas de Discriminação Racial que obriga os Estados (art. $4^{\circ}$, b) "a declarar como delitos puníveis por lei, qualquer difusão de ideias baseadas na superioridade ou ódio raciais, qualquer incitamento à discriminação racial, assim como quaisquer atos de violência ou provocação a tais atos, dirigidos contra qualquer raça ou qualquer grupo de pessoas de outra cor ou de outra origem étnica, como também qualquer assistência prestada a atividades racistas".

Não resta outra teorização se não considerar todos os tratados internacionais ratificados e incorporados pelo Brasil instituem os parâmetros de criminalização do ódio como igualmente relevantes e complementares para o combate do racismo e da discriminação em sua concepção mais ampla possível. O que deve prevalecer neste caso é a máxima efetividade na tutela dos direitos fundamentais e não mera constrição pela incompatibilidade na Convenção Americana de Direitos Humanos, na medida em que os critérios nela existentes são alargados pelas demais referências.

Complementa Neves (2012, p. 251-252) ressaltando a importância da escala internacional na implementação da tutela das graves violações dos direitos fundamentais:

\footnotetext{
Assim como a reação a violações escandalosas e flagrantes aos direitos humanos que se manifestam, por exemplo, na tortura e no genocídio, constitui um dos mais importantes indícios de um sistema jurídico mundial [...] trata-se do paradoxo da afirmação de expectativas normativas (contrafactuais) diante da própria prática que as contraria sistematicamente. A diferença reside $\mathrm{n}$ o fato de que aqueles direitos humanos em sentido estrito, que se referem basicamente à proibição de ações violentas [...] são suscetíveis de institucionalização e, sobretudo, contam com perspectivas de positivação e implementação processual em escala mundial,
}

Revista Brasileira de Direito Internacional le-SSN: 2526-0219| Curitiba | v. 2 | n. 2 | p. 193 - 213 | Jul/Dez. 2016. 
especialmente na esteira de transformações no direito internacional [...].

Não obstante, Sabadell e Dimoulis (2003, p. 253-254) fazem a ressalva sobre a aplicação rígida do direito penal por cortes internacionais:

\begin{abstract}
A possibilidade de tribunais internacionais aplicarem sanções de natureza (e gravidade) penal causou grande satisfação, pois foi considerado que, dessa forma, o direito internacional adquiriria finalmente uma 'respeitabilidade' parecida à do direito interno, deixaria de ser um soft law graças ao poder de ordenar prisões, realizar processos e castigar duramente os transgressores.

Esse raciocínio é, ao nosso ver, totalmente equivocado. O direito penal não deveria ser considerado como uma comprovação do 'crescimento' do direito internacional. O conceito da eficácia social do direito não se confunde com a intensidade de suas sanções. [...] Nada acrescentaria à credibilidade do direito internacional a incorporação de normas penais, que permaneceriam 'no papel' por falta de vontade política ou seriam aplicadas conforme os desígnios dos poderosos e segundo considerados conjunturais.
\end{abstract}

Em geral o controle de constitucionalidade não costuma verticalizar-se para abranger a convencionalidade, embora tal inferência fosse recomendável. Não obstante, com maior naturalidade a jurisprudência pátria tem admitido em tais hipóteses (a invocação do Direito alienígena e internacional) tal como a própria jurisprudência dos tribunais constitucionais e das cortes internacionais, resultante da provável influência da acessibilidade de tal conteúdo com os aprimoramentos tecnológicos.

Nesta esteira, a Corte Interamericana tenta promover uma "cultura de direitos fundamentais" e objetiva a "constitucionalização do Pacto de San José da Costa Rica", apesar de suas próprias negativas sobre o tema (HENNEBEL, 2009, p. 91). Ademais, há um nexo escasso entre o controle de convencionalidade e o princípio da legalidade, conforme sua definição nas Constituições, pois o controle de convencionalidade, em última análise, propicia a supremacia da legislação internacional (que dever á ser analisada conjuntamente com a compatibilidade constitucional) e, por extensão, a própria solidificação da jurisdição das Cortes Internacionais (SEMINARA, 2009) ${ }^{13}$.

Fassbender (2007, p. 278) explica que:

The ius cogens perspective of international constitutional law is a particularly value-oriented one because all the rules presently recognized as ius cogens (in the

\footnotetext{
${ }^{13}$ Carnota (2012, p. 27) destaca que: "Theoretically, conventionality control must not does not address the problem of internal validity of laws; it must just examine their consistency with International Law so as to make them practical (effect utile). It is firmly based in ius cogens, which consists of the body of International Law peremptory customary rules."
} 
first place, the prohibitions on genocide ${ }^{14}$., aggression, slavery, and of trading in human beings, and the rights of peoples to self-determination) are substantive in nature and have a human rights dimension.

Anota Rothenburg (2013) que a interlocução do Direito Constitucional nacional e estrangeiro e destes com o Direito internacional, traduz um "diálogo de fontes" o qual é referido pelo autor por como "constitucionalismo internacional", ou “interconstitucionalidade" por Canotilho (2006, p. 266), "transconstitucionalismo" por Marcelo Neves (2012) ou como "cross-constitucionalismo" em Tavares (2009). Tal interlocução é indicada como uma das características do neoconstitucionalismo: a "tendência expansiva" do constitucionalismo, um "constitucionalismo transnacional" (ARAGON REYES13, 2007, p. 38-39) ${ }^{15}$, já Pagliarini (2009, p. 126) teoriza “constitucionalismo supranacional”, com enfoque na experiência da União Europeia. Forma-se uma plataforma partilhada, com o "estabelecimento de uma espécie de 'gramática' jurídico-constitucional comum", a partir da "aproximação cada vez maior entre as diversas ordens constitucionais nacionais", como menciona Sarlet (2009, p. 167-168).

Cabe também relembrar que o Supremo Tribunal Constitucional já fez referência à convencionalidade no próprio julgamento do Habeas Corpus 82.424-2/RS, oportunidade na qual foi ressaltada a adesão da República Federativa a acordos e tratados multilaterais, que estabeleciam parâmetros de criminalização para o racismo. Destarte, o mesmo substrato ${ }^{16}$ poderá ser utilizado futuramente como fonte para o aporte de novas minorias à acepção do ódio nos delitos da Lei 7.716/89.

\footnotetext{
${ }^{14}$ A punição dos responsáveis após a queda de um regime totalitário, conforme denomina-se justiça de transição, demanda a análise da aplicabilidade da legislação válida no período ditatorial ou retroativo à este, acarreta conflitos de ordem política e jurídica, como é contestado nos Tribunais de Nuremberg e mais recentemente no caso da Argentina. Dimoulis analisa "o caso dos denunciantes invejosos" arrematando os diferentes posicionamentos sobre a conveniência e necessidade da reprimenda penal em tais casos. Vide: DIMOULIS, Dimitri. O Caso dos Denunciantes Invejosos. São Paulo: Revista dos Tribunais, 2003.

${ }^{15}$ Aragon Reyes (2013, p. 11-12) teoriza: "Existe, finalmente, otra característica (que es másuna consecuencia) del constitucionalismo que debe destacarse: el rango de fenómeno no ya puramen te nacional, sino transnacional, que ha ido adquiriendo en las últimas décadas. Se está asistiendo en nuestro tiempo al proceso de "constitucionalización" de determinadas organizaciones internacionales, con la consiguiente creación de jurisdicciones que, por en cima de los Derechos internos nacionales, aplican y defienden no sólo unas peculiares "Constituciones supranacionales" configuradoras de un orden "comunitario" interestatal (ya consolidado, por ejemplo, en la Unión Europea), sino ese otro tipo de "Constituciones tra nsnacionales”, como fueron llamadas hace ya más de treinta años por M. Capelletti14, que son las declaraciones, pactos, tratados o convenios internacionales sobre derechos humanos, cuya vigencia se ha venido assegurando incluso mediante la existencia de unos tribunales supraestatales capaces de interpretarlos y aplicarlos (el europeo de Estrasburgo y el americano de San José de Costa Rica, por ejemplo). En tal sentido es posible hablar hoy no sólo de una tendencia "expansiva" de los constitucionalismos nacionales, fenómeno que resulta evidente, sino de un verdadeiro "constitucionalis mo trasnacional”, como antes se apuntó."

${ }_{16}$ Arremata Rothenburg (2013, p. 685) sobre o uso das fontes internacionais como a lei e a jurisprudência em um novo panorama do neoconstitucionalismo: "Aproveitam-se os documentos legislativos (leis) e as experiências judiciais (jurisprudência) alheias; aproximam-se inclusive os modelos institucionais (por exemplo, a existência de Cortes Constitucionais e suas homólogas Cortes Internacionais). [...] A invocação dos textos normativos alienígenas e das decisões judiciais estrangeiras e internacionais sobre questões jurídicas semelhantes significa o emprego de fontes de Direito diversas daquelas do Direito interno.”
} 
Como ressalta Figueiredo (2009), embora o alinhamento da jurisprudência doméstica à internacional se constitua como fenômeno incipiente, pela provável ausência de rigor metodológico, é um movimento de crescente evolução oferecendo uma via alternativa na aplicação de soluções de resguardo nos direitos fundamentais. Caso a norma internacional atenda de forma mais satisfatória os parâmetros do sistema constitucional de garantias e direitos fundamentais, o Supremo Tribunal poderá lhe atribuir primazia, no sentido de reconduzir a jurisprudência interna (funções indicativa e substitutiva do Direito Internacional).

A ressalva Rothenburg (2013, p. 689) verte-se no sentido de que o Direito Internacional não se estabelece como absoluto:

\begin{abstract}
Não se trata, contudo - e é sempre importante ressaltar -, da impossibilidade de contrastar o Direito Internacional. O critério decisivo, também aqui, não é o da superioridade formal e apriorística de algum dos âmbitos do Direito, seja o interno, seja o internacional. Nem pruridos nacionalistas de uma defesa intransigente da soberania estatal, nem laivos universalistas de uma intrínseca bondade da comunidade das nações. [...] Importa verificar qual ordenamento melhor atende os direitos fundamentais.
\end{abstract}

A obrigatoriedade de adoção de medidas legislativas e institucionais - mandado internacional de criminalização - foi considerada pela Corte Interamericana de Direitos Humanos como um princípio "evidente e universalmente válido" ${ }^{17}$, que implica na conjunção de dois parâmetros distintos: I) a revogação de normas e práticas de qualquer natureza que impliquem em violações de garantias e direitos fundamentais previstos na Convenção, e II) a adoção de normas e práticas que efetivamente garantam tais direitos ${ }^{18}$. A Corte adotou o entendimento que a omissão legislativa ou a proteção legal (incluindo a esfera criminal) insuficiente para inibir as práticas colidentes coma Convenção ${ }^{19}$, pode ser suprida pela modificação ${ }^{20}$ ou emenda $^{21}$ de tais leis (RUIZ-CHIRIBOGA, 2010).

\footnotetext{
${ }^{17}$ Ruiz-Chiriboga (2010, p. 201): "According to the Court under the law of nations, a customary law prescribes that a State that has signed an international agreement must introduce into its domestic laws whatever changes are needed to ensure execution of the obligations it has undertaken. This principle is universally valid and has been characterized in case law as an evident principle ('principe allant de soi'; Exchange of the Greek and Turkish populations, advisory opinion, 1925, PCIJ, series B, no. 10, p. 20)". Vide Garrido and Baigorria vs. Argentina [1998]; La Cantuta vs. Peru [2006]; Almonacid-Arellano and others. vs. Chile [2006].

${ }^{18}$ Castillo-Petruzzi and others vs. Peru [1999]; Almonacid-Arellano and others vs. Chile [2006].

${ }^{19}$ Caso 'The Last Temptation of Christ' - Olmedo-Bustos and others vs. Chile [2001].

${ }^{20}$ Hilaire, Constantine e Benjamin and others. vs. Trinidad and Tobago [2002].

${ }^{21}$ Raxcacó-Reyes vs. Guatemala [2005].
} 
As consequências na falha do Estado em converter a legislação criminal nos parâmetros indicados pelo tratado internacional, além do controle de convencionalidade, são indicados por Ruiz-Chiriboga (2010, p. 209-210):

\begin{abstract}
As can be seen, the non-observance by the national legislature to amend the law, as well as the unwillingness of the national authorities to carry out the conventionality control, which in turn a) perpetuate the failure of the State to comply with its international obligations; b) reproduce human rights violations, and therefore increase the number of victims; c) augment the amount of compensations that the State must pay to victims; d) increase the workload of the international tribunals that are by definition complementary to national courts, impeding the former to focus on other situations or cases in a more expeditious way, are, amongst others unnecessary consequences.
\end{abstract}

Não se pode relegar toda a expectativa jurisdicional à justiça internacional, especialmente nos casos paradigmas e na composição de precedentes pátrios das cortes constitucionais. Sabadell e Dimoulis (2003) lembram que a justiça internacional não é isenta de problemas de legitimação e eficiência. A distância dos poderes nacionais constituídos e dos espaços de debate público de cada nação torna mais abstrato o controle político e jurídico. Existe também o risco de que a independência da justiça internacional transforme-se em plena autonomização. Situação esta em que a Corte torna-se alheia aos anseios das populações, ficando imune às críticas, do prisma das exigências democráticas.

Além disto, a citada autonomização indevidamente instituir a submissão de fato da jurisdição internacional aos interesses de certas nações ou coalisões de pressão, transformando o direito internacional em órgão a serviço de seus interesses. Outrossim, esta influência poderá ser exercida na própria composição dos tratados e convenções internacionais, de modo em que a imposição de deter minado conteúdo se submeta ao prisma jurídico que entende adequado a nação com maior articulação (SABADELL; DIMOULIS, 2003). Sustentamos que o fenômeno ocorre justamente na própria construção da Convenção Americana de Direitos Humanos no que tange aos limites da liberdade de expressão e criminalização do discurso de ódio, observando-se idêntico fenômeno em parte dos precedentes da Corte Interamericana, influenciado pelo governo norte-americano com base nos precedentes da Suprema Corte que se baseiam na interpretação da Primeira Emenda.

Ao encontro de tais apontamentos é que o controle convencional, exercido tanto pela esfera interna quanto pelo órgão internacional, mostra-se abalizado para a resolução das questões de conflitos de direitos fundamentais, acrescentando-se nesta fórmula a própria 
influência dos precedentes estrangeiros e internacionais na composição do direito (princípios, leis e jurisprudência).

Já Brum (2008, p. 337-338) acautela que:

\begin{abstract}
Moreover, even where the international community agrees on a universally held norm, it must still wrestle with the need to balance other competing norms. This ordering problem exhibits itself through what scholars have termed the "fragmentation" of international legislation, meaning the existence of different and somewhat autonomous rationales underlying a variety of regimes each proclaimed to be universal. [...] These regimes often conflict in their particular principles and institutions, their procedures and preferences, and their primary goals. [...] Since the patchwork legislative process of treaty-making is incoherent and inconsistent, the norms enshrined by one treaty can conflict with those underlying another multilateral treaties.
\end{abstract}

Aponta Ruiz-Chiriboga (2010) que, via de regra, quando o tribunal nacional se depara com a possibilidade de aplicar a norma com base em uma interpretação que colocaria o Estado em posição de colisão com tratado internacional ratificado (contrária ao conteúdo da convenção) ou outra condizente com as obrigações internacionais fïrmadas, deverá prevalecer a segunda hipótese; a harmonização da jurisprudência com as normas internacionais evita o controle de convencionalidade. O Comitê de Direitos Humanos das Nações Unidas apontou que "o gozo dos direitos reconhecidos no âmbito do Pacto Internacional sobre Direitos Civis e Políticos pode ser efetivamente garantido pelo judiciário de diversas maneiras, incluindo a aplicabilidade direta do Pacto, a harmonização comparada de textos constitucionais ou outras provisões legais, ou o efeito hermenêutico do Pacto na aplicação no direito nacional ${ }^{22 "}$ (HRC, 2004, p. 15).

Já o Comitê da ONU Contra a Tortura também declarou que "discrepâncias relevantes entre o conceito de tortura aportado pela legislação nacional e o recomendado na Convenção contra a Tortura e Outros Tratamentos ou Penas Cruéis, Desumanos ou Degradantes (incorporado pelo Brasil no Decreto $\mathrm{n}^{\circ} 6.085$ de 19 de abril de 2007) podem criar hiatos iminentes ou potenciais para a impunidade. Em alguns casos, embora a similaridade linguística utilizada, o significado pode ser qualificado pelas nuanças da legislação nacional ou pela interpretação judicial dada ao caso, pugnando o presente Comitê para que todos os Estados-parte assegurem a harmonização estrita de sua legislação com o

\footnotetext{
${ }^{22}$ HRC (General Comment No. 31 on the nature of the general legal obligation imposed on States Parties to the Covenant) 26 May 2004, UN Doc, CCPR/C/21/Rev.1/Add.13, § 15 .
}

Revista Brasileira de Direito Internacional le-SSN: 2526-0219| Curitiba | v. 2 | n. 2 | p. 193 - 213 | Jul/Dez. 2016. 
sentido previsto na Convenção ${ }^{23 "}$ (CAT, 2008, p. 3, grifo nosso).

Tais fontes levam ao reconhecimento dos próprios comitês da ONU acerca da insuficiência da ratificação dos tratados ou convenções internacionais como fator único para a harmonização no tratamento de graves violações dos direitos fundamentais. Outras variantes tais como a própria construção das leis nacionais, bem como a interpretação dada pelos tribunais (principalmente as cortes constitucionais) influenciam para que haja um desarranjo entre a previsão convencional e a jurisprudência de cada Estado. A criminalização do racismo e do ódio no Brasil não é diferente: oposições diametrais são encontradas na comparação da Lei 7.716/1989 em relação a todo o arcabouço normativo de tratados incorporado no bloco de constitucionalidade.

Embora as Cortes Internacionais busquem uma consistência recíproca em seus precedentes, é possível que duas ou mais jurisdições internacionais obtenham conclusões diferentes a respeito do mesmo direito ou liberdade. Invariavelmente a divergência verter-seá na interpretação ou hierarquização dos direitos fundamentais ${ }^{24} \mathrm{em}$ conflito ou em razão da construção normativa das respectivas convenções ${ }^{25}$. Ratifica-se que os conflitos entre tratados são uma consequência natural da fragmentariedade do Direito Internacional. Como aponta o Comitê de Direito Internacional da ONU (ILC), como um sistema jurídico complexo, o direito internacional não consiste da mera compilação aleatória de normas, mas na confluência de relações reciprocamente harmoniosas. As normas convencionais podem existir em um patamar hierarquicamente superior ou inferior, e sua formulação pode envolver maior ou menor abstração ou especificidade (RUIZ-CHIRIBOG A, 2010; SADAT-AKHAVI 2003).

Unificados em um mesmo objetivo, o resguardo dos direitos fundamentais, os instrumentos internacionais compõe um códex de normas, princípios e regras de alta complexidade. Diferentes frentes de aplicação mundial ou regional, tais como a Organização das Nações Unidas, Convenção Interamericana, Europeia, além de outras agências especializadas, destinam a tutela do direito com distinções claras com relação a seus beneficiários, e também conteúdo, força e efeitos jurídicos variáveis. A coexistência de

\footnotetext{
${ }^{23}$ CAT (General Comment No. 2 on the implementation of article 2 by States parties) 24 January 2008, UN Doc. CAT/C/GC/2, § 9.

${ }^{24}$ Ruiz-Chiriboga (2010, p. 217) utiliza a expressão "scope of a right or the threshold that should be applied to assess the admissibility of a restriction [of fundamental rights]".

${ }^{25}$ Segundo o entendimento de Sadat-Akhavi (2003, p. 220) o princípio da provisão mais favorável na tutela dos direitos humanos deve ser relativizado nos termos em que "even in these cases, the principle suffer two exceptions: when its application entails discrimination or endangers a paramount interest of society as whole". Nestas duas exceções, o balanceamento deve ser analisado individualmente nos casos de conflito.
}

Revista Brasileira de Direito Internacional le-SSN: 2526-0219| Curitiba | v. 2 | n. 2 | p. 193 - 213 | Jul/Dez. 2016. 
instrumentos de vocação internacional (global) é importante para a aplicação, de fato, do sistema de garantias e direitos fundamentais nas nações (STEINER, 2000). Tal composição é importante para o estabelecimento de uma padronização ou quesitos mínimos para a criminalização das condutas atentatórias a tais direitos, como na hipótese dos crimes de ódio e intolerância.

Ratifica-se o posicionamento adotado por Ruiz-Chiriboga (2010, p. 219) que a harmonização das normas nacionais e internacionais e o controle de convencionalidade devem ser direcionados para o vetor único da máxima efetividade dos direitos fundamentais: "If national courts find a conflict between two treaties - or between the interpretations of those treaties -, they shall [...] solve the case in a manner that the human right at stake is best protected".

\section{CONLUSÃO}

Concluiu-se que atualmente a convencionalidade vem ganhando um papel importante para maximização dos direitos fundamentais, especialmente quando determinado direito figura em uma pletora de tratados internacionais de conteúdo ligeiramente distinto. Tal fenômeno afeta, invariavelmente, as decisões das Cortes Internacionais, quando o direito nacional se mostra insuficiente ou leniente para resolver determinados conflitos.

Embora tais Cortes busquem uma consistência recíproca em seus precedentes, é possível que jurisdições internacionais obtenham conclusões distintas na deliberação sobre a prevalência de dois ou mais direitos ou liberdades. No caso do discurso de ódio, tal distinção torna-se ainda mais evidente. Enquanto a Corte Europeia interpreta as proibições no discurso de ódio por dois modelos distintos (proibição do discurso de ódio por abuso do direito de expressão - art. 17; relativização da liberdade de expressão, restringindo e limitando a prática à luz da igualdade negativa - art. $10 \S 2^{\circ}$ ), não há um padrão jurisprudencial sedimentado na Corte Interamericana, que tardiamente vem admitindo restrições civis e penais a tais práticas.

De outra banda, a incorporação de tratados de combate à discriminação no bloco de constitucionalidade brasileiro não observou a adequada tradução do mandado internacional, desembocando em um menor acesso de pleitos nacionais à jurisdição interamericana. Verifica-se a ocorrência do transconstitucionalismo, já que a ordem nacional contempla a proibição ao discurso de ódio consistente em qualquer forma de propaganda a favor da

Revista Brasileira de Direito Internacional le-SSN: 2526-0219| Curitiba | v. 2 | n. 2 | p. 193 - 213 | Jul/Dez. 2016. 
guerra, a apologia ao ódio nacional, racial ou religioso que constitua incitamento à discriminação, à hostilidade, ao crime ou à violência. Por outro lado, a interpretação mais adequada do dispositivo convencional deveria levar à interpretação da vedação ao ódio religioso, racial ou nacional que constituam incitação à violência ilícita ou qualquer outra ação similar, contra pessoa ou grupo, em razão de sua raça, cor, religião, idioma ou origem nacional.

Para suprir tal hiato é imprescindível que a construção legislativa e o acesso ao judiciário no caso de crimes de ódio não seja realizado com base unicamente no Direito pátrio, sendo necessária uma harmonização normativa e jurisprudencial com base nos tratados e convenções já ratificados pelo Brasil e, consequentemente, a construção de um adequado controle de convencionalidade na criminalização do ódio.

\section{REFERÊNCIAS}

ALVES, Fernando de Brito. A Construção Histórico-Discursiva do Conteúdo JurídicoPolítico da Democracia Como Direito Fundamental. 2012. 370 f. Tese (Doutorado em Direito) - Centro Universitário de Bauru - ITE, Programa de Pós-Graduação Stricto Sensu em Direito, Bauru, 2012.

ARAGON REYES, Manuel. La constitución como paradigm a. In: CARBONELL, Miguel (Coord.). Teoría del neoconstitucionalismo. Ensayos escogidos. Madrid: Trotta, 2007.

Neoconstitucionalismo y Garantismo. Tribunal Constitucional del República Dominicana. 2013.2 Disponível em: $<$ http://www.tribunalconstitucional.gob.do/sites/default/files/documentos/Manuel\%20Aragon \%20Reyes_Neoconstitucionalismo\%20y\%20garantismo.pdf>. Acesso em: 04. jun. 2016.

BOYLE, Kevin. Hate Speech: The United States versus the rest of the world? In: Maine Law Review, v. 53, n. 2, 2001.

BRUM, Gabriella. Bilateralism, Multilateralism, and Architecture of International Law. Harvard International Law Journal. v. 49. n. 2. 2008. p. 323-380. Disponível em: <http://dash.harvard.edu/bitstream/handle/1/10880577/HILJ_49-2_Blum.pdf?sequence=1>.

Acesso em: 30. jun. 2016.

CARNOTA, Walter F. The Inter-american Court of Human Rights and "Conventionality Control". 24. jul. 2012. Social Science Research Network - SSRN. Disponível em: <http://dx.doi.org/10.2139/ssrn.2116599>. Acesso em: 29. jun. 2016.

CAT. General Comment $\mathbf{N}^{0} 2$ on the implementation of article 2 by States parties. 24. 
jan. 2008. UN Doc. CAT/C/GC/2. United Nations. Disponível em: <http://www.refworld.org/pdfid/47ac78ce2.pdf>. Acesso em: 30. jun. 2016.

CONSELHO DA EUROPA. Convenção para Proteção dos Dir eitos do Homem e das Liberdades Fundamentais. Conselho da Europa - Gabinete de Documentação e Direito Comparado. 1950. Disponível em: <http://www.gddc.pt/direitos-humanos/textosinternacionais-dh/tidhregionais/conv-tratados-04-11-950-ets-5.html>. Acesso em: 08 jun. 2016.

CONVENÇÃO Americana de Direitos Humanos (1969): Pacto de San José da Costa Rica. Tratado Internacional. Procuradoria Geral do Estado de São Paulo. Disponível em: <http://www.pge.sp.gov.br/centrodeestudos/bibliotecavirtual/instrumentos/sanjose.htm>.

Acesso em: 10. mar. 2015.

CONVENCION Americana Sobre Derechos Humanos. Departamento de Derecho Internacional. 1969. Organización de los Estados Americanos. Disponível em: <http://www.oas.org/dil/esp/tratados_B-

32_Convencion_Americana_sobre_Derechos_Humanos.htm>.Acesso em: 19.jul. 2015.

DIMOULIS, Dimitri. O Caso dos Denunciantes Invejosos. São Paulo: Revista dos Tribunais, 2003.

FIGUEIREDO, Marcelo. Notas a respeito da utilização de jurisprudência estrangeira pelo Supremo Tribunal Federal no Brasil. Revista Brasileira de Estudos Constitucionais RBEC, Belo Horizonte, ano 3, n. 12, p. 57-69, out./dez. 2009.

Hate Speech. European Court of Human Rights. nov. 2014. Disponível em: <http://www.echr.coe.int/Documents/FS_Hate_speech_ENG.pdf>. Acesso em: 03. jun. 2016.

HRC. General Comment $\mathbf{N}^{\mathbf{0}} 31$ on the nature of the general legal obligation imposed on States Parties to the Covenant. 26. maio 2004. UN Doc, CCPR/C/21/Rev.1/Add.13. Human Rights Library. University of Minnesota. Disponível em: <https://www1.umn.edu/humanrts/gencomm/hrcom31.html>. Acesso em: 30. jul. 2015.

NEVES, Marcelo. Transconstitucionalismo. São Paulo: Martins Fontes, 2012.

OC-5/85 ADVISORY Opinion. Inter-American Court of Human Rights. Procuradoria Geral da República. 1985. Disponível em: <http://pfdc.pgr.mpf.mp.br/temas-deatuacao/comunicacao-social/radios-comunitarias/docs-documentos-tecnicos-de-outrosorgaos/opniao_consultiva_5.85_advisory_opinion_05_cidh.pdf>. Acesso em: 16. jun. 2016.

ONU. Declaração Sobre a Eliminação de Todas as Formas de Intolerância e Discriminação Fundadas na Religião ou nas Convicções. Assembleia Geral das Nações Unidas. $1981 . \quad$ Disponível em: $<$ http://www.oas.org/dil/port/1981Declara\%C3\%A7\%C3\%A3o\%20sobre\%20a\%20Elimina\% C3\%A7\%C3\%A3o\%20de\%20Todas\%20as\%20Formas\%20de\%20Intoler\%C3\%A2ncia\%20e \%20Discrimina\%C3\%A7\%C3\%A3o\%20Baseadas\%20em\%20Religi\%C3\%A3o\%20ou\%20C

Revista Brasileira de Direito Internacional le-SSN: 2526-0219| Curitiba | v. 2 | n. 2 | p. 193 - 213 | Jul/Dez. 2016. 
ren\%C3\%A7a.pdf>. Acesso em: 19. jul. 2016.

PAGLIARINI, Alexandre Coutinho. Tratado de Lisboa: a significação de um novo Direito Constitucional?. Revista Brasileira de Estudos Constitucionais - RBEC, Belo Horizonte, ano 3, n. 11, p. 115-135, jul./set. 2009.

ROTHENBURG, Walter Claudius. Constitucionalidade e Convencionalidade da Lei de Anistia Brasileira. Revista Direito GV, São Paulo, v. 9. n. 2, jul./d ez., 2013, p. 681-706. Disponível em: $<$ http://bibliotecadigital.fgv.br/ojs/index.php/revdireitogv/article/view/21449/20206>. Acesso em: 29. jul. 2015.

RUIZ-CHIRIBOGA, Oswaldo. The Conventionality Control: Examples of (Un)Successful Experiences in Latin-America. 2010.

SABADELL, Ana Lucia; DIMOULIS, Dimitri. Tribunal Penal Internacional e Direitos Fundamentais: Problemas de Constitucionalidade. Cadernos de Direito - Universidade Metodista de Piracicaba (UNIMEP), Piracicaba, ano 3, n. 5, p. 241-259, jul./dez. 2003.

SADAT-AKHAVI, Seyed Ali. Methods of Resolving Conflicts between Treaties. HEI Graduate Institute of International Studies Geneva: Martinus Nijhoff Publishers, 2003.

SARLET, Ingo Wolfgang. A assim designada proibição de retrocesso social e a construção de um direito constitucional comum latino-americano. Revista Brasileira de Estudos Constitucionais - RBEC, Belo Horizonte, ano 3, n. 11, p. 167-204, jul./set. 2009.

STEINER, Sylvia Helena de Figueiredo. A Convenção Americana sobre Direitos Humanos e sua Integração ao Processo Penal Brasileiro. São Paulo: Revista dos Tribunais, 2000.

WEBER, Anne. Manual on Hate Speech. Strasboug: Council of Europe Publishing, 2009. 